\title{
Glacier volume response time and its links to climate and topography based on a conceptual model of glacier hypsometry
}

\author{
S. C. B. Raper $^{1}$ and R. J. Braithwaite ${ }^{2}$ \\ ${ }^{1}$ Centre for Air Transport and the Environment, Manchester Metropolitan University, Manchester, M1 5GD, UK \\ ${ }^{2}$ School of Environment and Development, University of Manchester, Manchester M13 9PL, UK \\ Received: 12 January 2009 - Published in The Cryosphere Discuss.: 4 March 2009 \\ Revised: 20 July 2009 - Accepted: 10 August 2009 - Published: 14 August 2009
}

\begin{abstract}
Glacier volume response time is a measure of the time taken for a glacier to adjust its geometry to a climate change. It has been previously proposed that the volume response time is given approximately by the ratio of glacier thickness to ablation at the glacier terminus. We propose a new conceptual model of glacier hypsometry (areaaltitude relation) and derive the volume response time where climatic and topographic parameters are separated. The former is expressed by mass balance gradients which we derive from glacier-climate modelling and the latter are quantified with data from the World Glacier Inventory. Aside from the well-known scaling relation between glacier volume and area, we establish a new scaling relation between glacier altitude range and area, and evaluate it for seven regions. The presence of this scaling parameter in our response time formula accounts for the mass balance elevation feedback and leads to longer response times than given by the simple ratio of glacier thickness to ablation at the terminus. Volume response times range from decades to thousands of years for glaciers in maritime (wet-warm) and continental (dry-cold) climates respectively. The combined effect of volume-area and altitude-area scaling relations is such that volume response time can increase with glacier area (Axel Heiberg Island and Svalbard), hardly change (Northern Scandinavia, Southern Norway and the Alps) or even get smaller (The Caucasus and New Zealand).
\end{abstract}

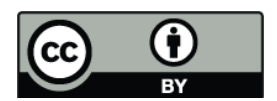

Correspondence to: S. C. B. Raper (s.raper@mmu.ac.uk)

\section{Introduction}

Global warming is causing increased melt of grounded ice and contributing to sea level rise (Meier, 1984; IPCC, 2007). For projections of future sea-level rise, there are two stages in the modelling of glacier response to climate change (Warrick and Oerlemans, 1990). Firstly, to calculate changes in mass balance over present glacier areas (static response) and secondly to account for the changing glacier area and volume (dynamic response) that result from the mass balance changes. Earlier projections of sea-level only took account of the static response, e.g. as modelled by Oerlemans and Fortuin (1992) and Oerlemans (1993), while more recent assessments also include attempts to account for dynamic response (Van de Wal and Wild, 2001; Raper and Braithwaite, 2006).

The classic approach to changes in glacier volume as a result of climate forcing is to solve partial differential equations for glacier dynamics and thermodynamics. This can be done analytically for simplified glacier geometry (Nye, 1963) but will generally require numerical methods. Numerical solutions of differential equations are difficult to apply to the several hundred thousand mountain glaciers and ice caps that contribute to rising sea level (Bahr, 2009). For example, Oerlemans et al. (1998) apply dynamic flow models to 12 glaciers and say "No straightforward relationship between glacier size and fractional change of ice volume emerges for any given climatic scenario. The hypsometry of individual glaciers and ice caps plays an important role in their response, thus making it difficult to generalize results". More detailed dynamic flow modelling of glaciers will undoubtedly contribute to our better understanding of individual glaciers but for an overall view of sea level rise from glaciers several authors have proposed the alternative use of more conceptual models with volume-area scaling (Van de

Published by Copernicus Publications on behalf of the European Geosciences Union. 
Wal and Wild, 2001; Raper and Braithwaite, 2006) that can be applied to a whole spectrum of glacier geometries.

Glacier volume response time is a measure of the time taken for a glacier to adjust its geometry to a climate change (Jóhannesson et al., 1989a; Oerlemans, 2001) and is implicit in the solution of numerical models, e.g. the response to a step change in mass balance (Nye, 1963). However, a number of authors have sought to express volume response time analytically as a relatively simple function of climate and glacier geometry (Jóhannesson et al., 1989a; Raper et al., 1996; Bahr et al., 1998; Pfeffer et al., 1998; Harrison et al., 2001; Oerlemans, 2001). Such functions should allow us to estimate characteristic response times for different glacier regions from their climatic and topographic settings.

The response time $\tau$ according to Jóhannesson et al. (1989a) is given in Eq. (1):

$$
\tau=\frac{H}{-b_{t}}
$$

Where " $H$ is a thickness scale of the glacier and $-b_{t}$ is the scale of the ablation along its terminus" in the words of Jóhannesson et al. (1989a). Paterson (1994, p. 320) applies Eq. (1) to estimate response times for three classes of glacier: glaciers in temperate maritime climate, ice caps in arctic Canada and for the Greenland ice sheet. The resulting response times are respectively $15-60,250-1000$ and $3000 \mathrm{a}$. The short response time for the first class (with smallest area?) is noteworthy because a theoretical analysis by Nye (1963) concluded that alpine glaciers have response times of several hundred years. Paterson (1994, p. 320-321) cites the classic graph of percentage advancing/retreating glaciers in the Alps over the past century as evidence for quite short response times for Alpine glaciers, i.e. less than 20 a. However, in a comment on our original paper, Kuhn (2009) suggests that this graph only shows short-term variations in mass balance forcing and that we cannot necessarily infer short response times from this evidence. Jóhannesson et al. (1989b) extend the approach of Jóhannesson et al. (1989a) by analysing the apparent discrepancy in response times between their formula, i.e. Eq. (1) in our paper, and expressions derived by Nye (1963) from kinematic wave theory. Apparently "... using kinematic wave theory involves difficult problems concerning details of behaviour at the terminus" (Jóhannesson et al., 1989b).

Analytical formulations of glacier response time depend upon conceptual models of the glacier that should be realistic but simple enough to yield an analytical solution. Callendar (1950 and 1951) was an early pioneer of conceptual models in glaciology and was able to explain some aspects of glacier behaviour with "back of the envelope" calculations. However, there can be a "law of unintended consequences" such that a simplification in the model (introduced to make calculations easier) excludes glacier behaviour that is relevant to the real world. For example, Jóhannesson et al. (1989a) admit that their approach neglects the positive feedback that arises when an initial mass balance perturbation causes a change in glacier surface altitude such that the mass balance perturbation changes. Harrison et al. (2001) address this problem by deriving a form of Eq. (1) that includes a term that explicitly accounts for changes in glacier surface altitude. Their derivation is based on the concept of the glacier reference surface balance described by Elsberg et al. (2001). One notable difference between their approach and ours is that they develop their argument in the coordinates of a map projection whereas our treatment looks at vertical profiles. The Harrison et al. (2001) approach assumes that the change in glacier area is in the vicinity of the glacier terminus, whereas in our approach we consider changes in the area-altitude distribution.

The thickness scale in Eq. (1) is loosely defined and Jóhannesson et al. (1989a) emphasise their approach is only intended to give order of magnitude estimates and Paterson $(1994$, p. 320) says the distinction "... between the mean and maximum ice thickness is insignificant at this order of precision". In addition, the differing effects of climate and glacier geometry in Eq. (1) are difficult to separate. For example, $H$ in Eq. (1) is clearly a geometrical property of the glacier but $b_{t}$ combines climatic and geometric properties. We therefore propose an improved derivation of the volume response time in Raper et al. (1996), where the climate and geometric parameters are separated, and the latter are clearly defined so that we can quantify them with data from the World Glacier Inventory (http://nsidc.org/data/glacier inventory). Our conceptual model is based upon the simplified model of glacier hypsometry (area-altitude relation) used by Raper and Braithwaite (2006), while Jóhannesson et al. (1989a) and Oerlemans (2001, Chapter 8) use crosssections (altitude versus downstream distance) of uniform width. Our model treats the mass balance of the whole glacier rather than mass balance near the terminus. We hope that our work follows the philosophy that it is "better to think exactly with simplified ideas than to reason inexactly with complex ones" (Nye, 1948).

\section{Conceptual model}

For a glacier in equilibrium with climate the mean specific mass balance, i.e. the area-averaged balance for the whole glacier (Anonymous, 1969) is zero. Its equilibrium line altitude (ELA) is $\mathrm{ELA}_{0}$ and its dimensions are constant with time (see Table 1 for model notation). The glacier has area $A_{0}$ and volume $V_{0}$. The mass balance is then suddenly perturbed by $\Delta b$ applied over the whole area of the glacier and the ELA instantly changes to ELA 1 , and the dimensions of the glacier slowly change to bring the glacier back into a new equilibrium state with area $A_{1}$ and volume $V_{1}$.

The conceptual model is sketched in Fig. 1. A negative change in mass balance of the whole glacier is represented in Fig. 1 by a shift in the balance-altitude profile which we 
Table 1. Description of model parameters.

\begin{tabular}{|c|c|}
\hline Parameter & Description \\
\hline$\Delta b$ & Change in mass balance ( $\mathrm{m}$ w.e. $\left.\mathrm{a}^{-1}\right)$ \\
\hline$\gamma$ & Volume-area scaling parameter (dimensionless) \\
\hline$\eta$ & Altitude range-area scaling parameter (dimensionless) \\
\hline$\tau$ & Response time of glacier (a) \\
\hline$\tau_{\text {JRW }}$ & Response time from Jóhannesson et al. (1989a) (a) \\
\hline$\tau_{R B}$ & Response time according to present study (a) \\
\hline$A$ & Area of glacier at any time $\left(\mathrm{km}^{2}\right)$ \\
\hline$A_{0}$ & Initial area of glacier $\left(\mathrm{km}^{2}\right)$ \\
\hline$A_{1}$ & Final area of glacier $\left(\mathrm{km}^{2}\right)$ \\
\hline $\bar{b}$ & Mean specific balance of glacier ( $\mathrm{m}$ w.e. $\mathrm{a}^{-1}$ ) \\
\hline$b_{t}$ & Specific balance at terminus ( $\mathrm{m}$ w.e. $\left.\mathrm{a}^{-1}\right)$ \\
\hline$D_{0}$ & Mean thickness of glacier before change of mass balance (m) \\
\hline ELA & ELA of glacier at any time $(\mathrm{m})$ \\
\hline $\mathrm{ELA}_{0}$ & ELA before change of mass balance $(\mathrm{m})$ \\
\hline $\mathrm{ELA}_{1}$ & ELA after change of mass balance $(\mathrm{m})$ \\
\hline$H$ & Thickness scale of glacier $(\mathrm{m})$ \\
\hline$k$ & Balance gradient ( $\mathrm{m}$ w.e. $\mathrm{a}^{-1} \mathrm{~m}^{-1}$ ) \\
\hline$R$ & Altitude range of glacier at any time $(\mathrm{m})$ \\
\hline$R_{0}$ & Initial altitude range $(\mathrm{m})$ \\
\hline$R_{1}$ & Final altitude range $(\mathrm{m})$ \\
\hline$V$ & Volume of glacier at any time $\left(\mathrm{km}^{3}\right)$ \\
\hline$V_{0}$ & Initial volume of glacier $\left(\mathrm{km}^{3}\right)$ \\
\hline$V_{1}$ & Final volume of glacier $\left(\mathrm{km}^{3}\right)$ \\
\hline
\end{tabular}

assume is linear over the whole glacier. The new ELA of the glacier, $\mathrm{ELA}_{1}$, depends upon the magnitude of the mass balance perturbation and the balance gradient $k$, such that:

$\mathrm{ELA}_{1}=\mathrm{ELA}_{0}+\frac{\Delta b}{k}$

Figure 1 is drawn for a typical glacier in a dry part of the Alps where a temperature rise of $+1 \mathrm{~K}$ throughout the whole year causes a mass balance change of $-0.66 \mathrm{~m}$ water $a^{-1}$ and raises the ELA by $160 \mathrm{~m}$ (values from the model calculations for Braithwaite and Raper, 2007). The change in mass balance for a $1 \mathrm{~K}$ temperature rise is termed the temperature sensitivity of mass balance (Oerlemans and Fortuin, 1992: Braithwaite and Zhang, 1999; de Woul and Hock, 2005). Equation (2) could be applied to a mass balance change due to precipitation change and we would then use the precipitation sensitivity of mass balance. For the present paper we abbreviate 'temperature sensitivity of mass balance' to 'mass balance sensitivity' because we are only dealing with temperature changes.

Our conceptual model is simple but not unrealistic:

1. Balance gradients are not generally constant with altitude on real glaciers, reflecting effects of precipitation variations as well as wind drifting and avalanches. Balance gradients are also greater in the ablation area and

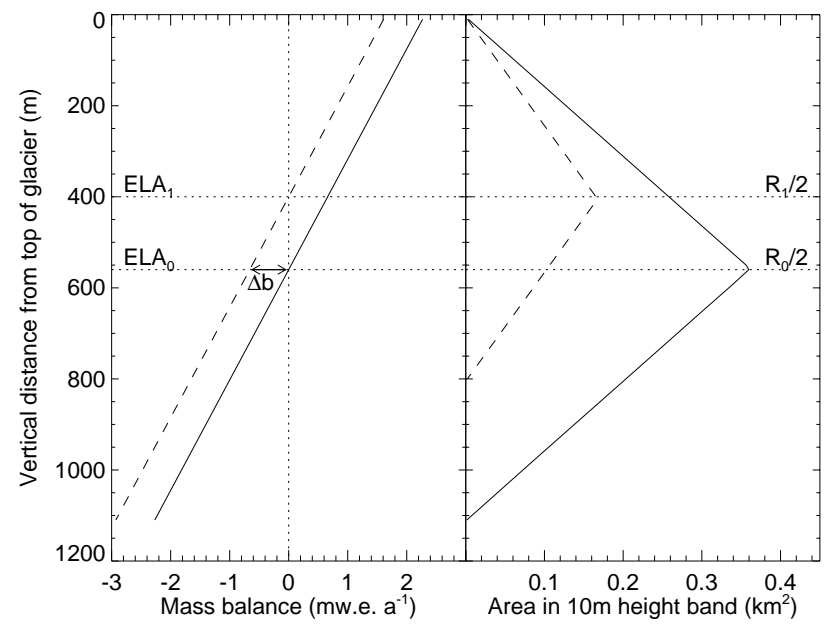

Fig. 1. Illustration of conceptual model of mass balance change by horizontal displacement of a linear relation between mass balance and altitude. Solid lines show the reference climate state 0 , dashed lines show the new perturbed climate equilibrium state 1 . The area altitude distribution is assumed to be symmetrical and triangular. 


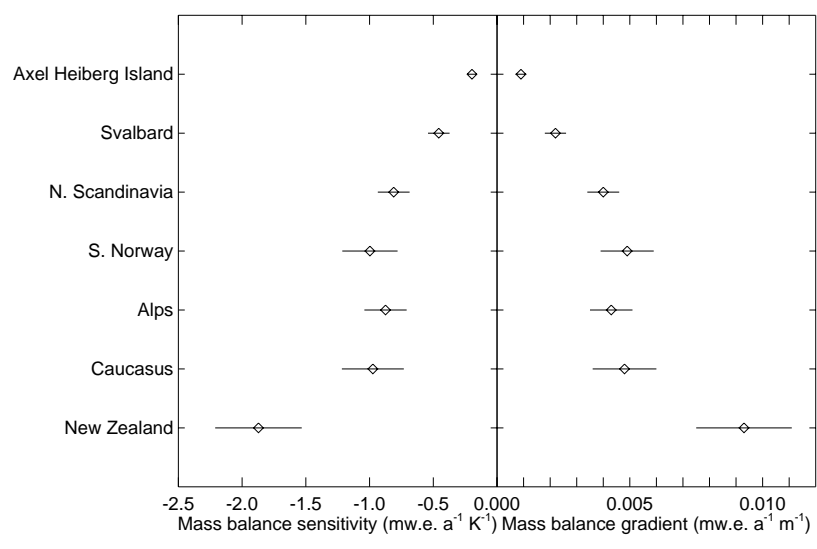

Fig. 2. Mass balance sensitivity and mass balance gradient represented by the activity index for the seven regions. Error bars are for \pm 1 standard deviation.

smaller in the accumulation area (Furbish and Andrews, 1984; Braithwaite and Raper, 2007). We assume a constant balance gradient here to derive an analytical solution for glacier volume change but for numerical modelling we can use the degree-day model to calculate non-linear balance-altitude relations, e.g. as in Braithwaite and Raper (2007).

2. Figure 1 shows triangular area-altitude distributions that are symmetrical about the ELA (Raper and Braithwaite, 2006) and we also assume that the glacier retains a symmetrical altitude distribution as it shrinks. We return to these points later in the paper with data from real glaciers to show these are reasonable first approximations.

3. The apex of the triangle in Fig. 1 is the median altitude of the glacier, dividing the glacier area into equal halves, and this coincides with the ELA when the glacier is in equilibrium (Meier and Post, 1962; Braithwaite and Müller, 1980). For a symmetric area-altitude distribution, the median altitude is also equal to the areaweighted mean altitude of the glacier (Kurowski, 1893).

4. For a linear balance-gradient, the specific mass balance at the median altitude (also the mean altitude) is equal to the mean specific mass balance (Kurowski, 1893; Braithwaite and Müller, 1980) which would be zero in the case of a glacier in equilibrium.

5. The assumption of linear balance-gradient is not as restrictive as it may first appear because glacier areas are generally largest near the median altitude, where there is maximum ice flux, and smallest at the top and bottom of the glacier where the linear assumption is most likely to be violated. This means that the area-weighted averaging of the balance-altitude function gives greatest weighting to altitudes near the median altitude. The $k$ parameter in Eq. (2) should therefore be regarded as representing the balance gradient across the ELA, i.e. the activity index of Meier (1962) or the energy of glacierization of Shumsky (1947). For many glaciers there is a strong correlation between mean specific balance and ELA and the slope of the regression equation is an estimate of balance gradient (Braithwaite, 1984).

We measure all heights downwards from the upper margin of the glacier which is assumed fixed when climate changes. This is a reasonable approximation for valley and mountain glaciers whose tops are constrained by hard rock topography. If the ELA rises above the top of the glacier the glacier will simply disappear before it reaches a new equilibrium (Pelto, 2006). From Fig. 2 in Paul et al. (2004) it can be seen that the lower margins of glaciers have retreated greatly in the period 1850-1998 while the upper margins have barely changed in general agreement with our assumption. The assumption of a fixed upper margin does not hold for ice caps since the maximum height of an ice cap changes with the ice cap thickness and the approach does not therefore apply to ice caps.

As the maximum altitude of the glacier is fixed, shrinkage of the glacier involves a rise in the minimum elevation, or a reduction in the altitude range $R$ between maximum and minimum altitudes of the glacier. As the glacier's area and volume shrink towards the new equilibrium state, the halfrange $(R / 2)$ moves from $R_{0} / 2$ at the old ELA to $R_{1} / 2$ at the new ELA. The mean specific mass balance of the glacier at any time, $\bar{b}$, is then equal to:

$\bar{b}=k \frac{\left(R_{1}-R\right)}{2}$

Equation (3) follows from Eq. (2) when the initial mass balance perturbation, $\Delta \mathrm{b}$, and initial altitude range $R_{0}$, are replaced by the time-evolving variables $\bar{b}$ and $R$. Measuring heights downwards, $R$ is bigger than $R_{1}$ and $\bar{b}$ is therefore negative and tends to zero as $\mathrm{R}$ approaches $R_{1}$.

The mass balance at the glacier terminus (altitude $R$ measured from the top of the glacier) at any time after the mass balance perturbation is given by

$b_{t}=k\left[\left(\frac{R_{0}}{2}\right)-R\right]+\Delta b$

The mass balance at the terminus is therefore a function of both climate (balance gradient, $k$ ) and glacier geometry (altitude range, $R$ ) and changes until it achieves a new steadystate value for $R=R_{1}$. The value of $R_{1}$ can be calculated from Eq. (2) by noting that $\mathrm{ELA}_{1}=R_{1} / 2$ and $\mathrm{ELA}_{0}=R_{0} / 2$ which gives:

$R_{1}=R_{0}+2\left(\frac{\Delta b}{k}\right)$

The total change in altitude of the terminus according to Eq. (5) is twice the change in ELA in Eq. (2). We return to the issue of the mass balance at the terminus at the end of 
this section and in a later section but start our analysis with the mean specific balance. The product of the glacier area A and mean specific balance, given by Eq. (3), gives the rate of change of glacier volume:

$\frac{d V}{d t}=A k \frac{\left(R_{1}-R\right)}{2}$

We treat ice dynamics implicitly by using geometric scaling following Chen and Ohmura (1990), Bahr et al. (1997), Raper et al. (1996, 2000), Van de Wal and Wild (2001), Raper and Braithwaite (2006) and Radic et al. (2007, 2008). We follow others in assuming that volume scales onto area as

$V \propto A^{\gamma}$

and we use a scaling relation between altitude range and area as implemented by Raper and Braithwaite (2006) so that

$R \propto A^{\eta}$

Bahr et al. (1997) estimate the scaling index $\gamma$ in Eq. (7) from depth-sounding observations on 144 glaciers and obtain an average of 1.36, which is in remarkable agreement with Chen and Ohmura (1990) who studied fewer glaciers. Bahr et al. (1997) also quote Russian authors for indices in the range 1.3 to 1.4. Paterson (1981 and 1994) gives indices of 1.25 and 1.5 respectively for theoretical profiles of ice caps and valley glaciers. The volume-area scaling of Bahr et al. (1997) has been criticised as it "correlates a statistical variable (area) with itself (area in volume)" (Haeberli et al., 2007; Lüthi et al., 2008) but we think it is a good example of an empirical relation with a sound physical background. The $\gamma$ value is greater than unity because average glacier depth increases with increasing glacier area.

From Eqs. (7) and (8) expressions for $A$ and $R$ can be derived in terms of $V$ and $V_{0}$, giving:

$$
\begin{aligned}
& A=A_{0}\left(\frac{V}{V_{0}}\right)^{\frac{1}{\gamma}} \\
& R=R_{0}\left(\frac{V}{V_{0}}\right)^{\frac{\eta}{\gamma}}
\end{aligned}
$$

Substitution of Eqs. (9) and (10) into Eq. (6) gives a new form of the volume change equation:

$$
\frac{d V}{d t}=A_{0}\left(\frac{V}{V_{0}}\right)^{\frac{1}{\gamma}} k\left(\frac{R_{0}}{2}\right)\left[\left(\frac{V_{1}}{V_{0}}\right)^{\frac{\eta}{\gamma}}-\left(\frac{V}{V_{0}}\right)^{\frac{\eta}{\gamma}}\right]
$$

If we now define a new volume variable $\mathrm{Y}$ by:

$$
Y=V^{\frac{\eta}{\gamma}}
$$

Then Eq. (11) may be written in more conventional linearresponse form involving an e-folding time, $\tau$, as:

$\frac{d Y}{d t}=\frac{\left(Y_{1}-Y\right)}{\tau}$
Where $Y_{1}$ and $Y$ are $V_{1}^{\eta / \gamma}$ and $V^{\eta / \gamma}$ respectively. $Y$ refers to the time evolving glacier volume while $Y_{1}$ refers to the new equilibrium volume towards which the volume is tending. The glacier volume response time, $\tau$, is defined as:

$\tau=\left(\frac{\gamma}{\eta}\right) D_{0}\left(\frac{2}{R_{0}}\right)\left(\frac{1}{k}\right)\left(\frac{V}{V_{0}}\right)^{\frac{(\gamma-1-\eta)}{\gamma}}$

where the mean glacier depth $D_{0}$ equals $V_{0} / A_{0}$. The last factor determines how the response time changes non-linearly with changing volume. However, for a glacier in or near its reference state, i.e. $V \approx V_{0}$ for small volume changes, the equation is simplified because the fifth factor becomes unity:

$\tau=\left(\frac{\gamma}{\eta}\right) D_{0}\left(\frac{2}{R_{0}}\right)\left(\frac{1}{k}\right)$

This is the form of the equation that we use later in the paper, but note that the last factor in Eq. (14) can also be used for calculating the response time for different volumes instead of redefining the reference values of $D_{0}$ and $R_{0}$ (cf. in Table 5). It is useful to briefly compare our formulation with that of Jóhannesson et al. (1989a). A more in-depth comparison is made in the next section.

In Eq. (15) the first factor $(\gamma / \eta)$ involves the scaling factors, the second factor $\left(D_{0}\right)$ represents glacier geometry before perturbation of mass balance, and according to Eq. (4) the inverse of the third and fourth factors $k\left(R_{0} / 2\right)$ represents $-b_{t}$ where $b_{t}$ is the balance at the terminus before perturbation of mass balance. Our response time Eq. (15) can therefore be expressed by:

$\tau=\left(\frac{\gamma}{\eta}\right)\left(\frac{D_{0}}{-b_{t}}\right)$

Comparing Eq. (16) with Eq. (1) from Jóhannesson et al. (1989a), shows that both equations involve a ratio of glacier depth or thickness to balance at the terminus. In the next section, we show an alternative approach to Eq. (16) that allows a closer look at the similarities and differences between Eqs. (16) and (1).

\section{An alternative approach}

We start by returning to the definition of volume response time $\tau$ in Jóhannesson et al. (1989a):

$\tau=\frac{\partial V}{\partial B}$

Where $\partial V$ is the difference in the steady state volume of the glacier before and after the mass balance perturbation, and $\partial B$ is the integral of the mass balance perturbation over the initial area of the glacier. Jóhannesson et al. (1989a) then give expressions for these parameters for some simplified glacier geometries. Their crucial assumption is that the initial mass balance perturbation of the whole glacier is balanced in 
Table 2. Summary data for the seven glacier regions. Based on data from World Glacier Inventory (http://nsidc.org/data/glacier_inventory).

\begin{tabular}{lllll}
\hline Region & Lat/Long & Mid-point altitude (m a.s.l.) & Glacier area $\left(\mathrm{km}^{2}\right)$ & Number of glaciers \\
\hline Axel Heiberg Island & $78-81^{\circ} \mathrm{N} 88-97^{\circ} \mathrm{W}$ & $50-2200$ & 11691 & 1094 \\
Svalbard & $77-81^{\circ} \mathrm{N} 11-32^{\circ} \mathrm{E}$ & $110-955$ & 33121 & 893 \\
Northern Scandinavia & $65-70^{\circ} \mathrm{N} 13-23^{\circ} \mathrm{E}$ & $290-2080$ & 1441 & 1487 \\
Southern Norway & $60-63^{\circ} \mathrm{N} 5-9^{\circ} \mathrm{E}$ & $600-2060$ & 1617 & 921 \\
The Alps & $44-47^{\circ} \mathrm{N} 60-14^{\circ} \mathrm{E}$ & $1750-4060$ & 3056 & 5331 \\
The Caucasus & $41-44^{\circ} \mathrm{N} 40-48^{\circ} \mathrm{E}$ & $1960-4990$ & 1398 & 1524 \\
New Zealand & $39-46^{\circ} \mathrm{S} 167-176^{\circ} \mathrm{W}$ & $1030-2770$ & 53481 & 137 \\
TOTAL & & & & 1587 \\
\hline
\end{tabular}

the new steady state by an area change at the glacier terminus over which the mean specific mass balance is the initial mass balance at the terminus $b_{t}$. We, however, can apply our conceptual model to Eq. (17) as follows:

$\partial V=\left(V_{1}-V_{0}\right)$

$\partial B=A_{0} k \frac{\left(R_{1}-R_{0}\right)}{2}$

Where $\partial B$ refers to the volumetric balance obtained by multiplying specific balances from Eq. (3) by glacier area.

Substituting the volume-area scaling Eq. (9) into Eq. (18) gives:

$\partial V=V_{0}\left[\left(\frac{A_{1}}{A_{0}}\right)^{\gamma}-1\right]$

For relatively small area changes, we can use a truncated McLaurin series to replace $\left(A_{1} / A_{0}\right)^{\gamma}$ with $1-\gamma\left[1-\left(A_{1} / A_{0}\right)\right]$. Substituting this linear approximation back into (20), with rearrangement and expressing $V_{0} / A_{0}$ as the mean depth of the glacier $D_{0}$ gives:

$\partial V=D_{0} \gamma\left[A_{1}-A_{0}\right]$

In a similar way:

$\partial B=k\left(\frac{R_{0}}{2}\right) \eta\left[A_{1}-A_{0}\right]$

Dividing Eq. (21) by Eq. (22) then gives us

$\tau=\frac{\left[D_{0} \gamma\right]}{\left[k\left(\frac{R_{0}}{2}\right) \eta\right]}$

This is identical to our original derivation in Eq. (15).

From an inspection of Eqs. (10) and (11) in Jóhannesson et al. (1989a), and translating into our notation, his thickness scale $H$ is given by:

$H=\left(\frac{d V}{d A}\right)\left(\frac{A_{0}}{V_{0}}\right) D_{0}$

Where $D_{0}$ is the mean depth of the glacier. Jóhannesson et al. (1989a) evaluate the expression $(d V / d A)\left(A_{0} / V_{0}\right)$ in terms of analytical solutions for simplified glacier geometry. We now evaluate this expression using the volume-area scaling method that was not available in its present form in 1989. Expressing $V$ as $V_{0} .\left(A / A_{0}\right)^{\gamma}$ and differentiating with respect to $A$, we find $(d V / d A)\left(A_{0} / V_{0}\right)=\gamma$. Therefore:

$H=\gamma D_{0}$

Substitution of Eq. (25) back into Eq. (1) gives the response time of Jóhannesson et al. (1989a) as:

$\tau_{\mathrm{JRW}}=\frac{\gamma D_{0}}{-b_{t}}$

Where $\tau_{\text {JRW }}$ denotes the response time according to Jóhannesson et al. (1989a).

Comparing Eq. (26) with Eq. (16) shows that:

$\tau_{R B}=\frac{\tau_{\mathrm{JRW}}}{\eta}$

Where $\tau_{R B}$ is the response time according to the present authors Raper and Braithwaite.

\section{The effects of climate change}

The effects of climate change on glacier volume are expressed by the mass balance sensitivity and the response time. The former defines the immediate change in mass balance caused by a particular change in temperature and the latter measures the speed at which the glacier volume adjusts to the climate change. The response time depends upon the mass balance gradient according to Eq. (15) as well as upon glacier dimensions.

We use mass balance sensitivities and gradients calculated with a degree-day model for seven regions (Braithwaite and Raper, 2007). The degree-day model is applied to the estimated ELA for half-degree latitude-longitude grid squares containing glaciers within each region. The estimated ELA for each grid square is the average of median altitude for all glaciers within the grid square. The regions (Table 2) were chosen for their good data coverage in the World Glacier Inventory. They include the five main glacial regions of Europe together with Axel Heiberg Island, Canada, and New 
Zealand, which were added to represent the extremes of cold/dry and warm/wet conditions.

Average and standard deviation of mass balance sensitivity and gradient are shown in Fig. 2 for the seven regions. The mass balance sensitivity and balance gradient both vary by about an order of magnitude. The mass balance model gives a very strong negative linear relationship between the mass balance sensitivity and the mass balance gradient $(r=-1.00)$ with low (negative) sensitivity and low gradient in dry-cold conditions and high (negative) sensitivity and high gradient in wet-warm conditions. The physical basis for the relationship is that the mass balance sensitivity is a change in the mass balance due to a temperature change whereas the mass balance gradient is a change in the mass balance due to an altitude change. Thus the relationship between mass balance sensitivity and mass balance gradient are to a large extent governed by the temperature lapse rate, see Kuhn (1989).

The link between the mass balance sensitivity and the glacier volume response time (through the mass balance gradient) has implications for long-term changes in glacier volume and global sea-level. It means that warm/wet glaciers with large mass balance sensitivity tend to have a small response time whereas cold/dry glaciers with small mass balance sensitivity tend to have a longer response time. This behaviour was noted by Raper et al. (2000) in sensitivity experiments. Thus temperature-sensitive glaciers show the most rapid response to climate change at present but may not be the most important contributors to sea level change in the long term.

\section{The effects of topography}

In this section, we analyse the World Glacier Inventory data to estimate the area vs altitude range scaling index values appropriate for the seven regions with their particular topographic relief. The World Glacier Inventory data mostly originates from measurements taken in the third quarter of the 20th Century ( 1950-1975). This was a time of relative glacier stability and the worldwide mass balance was probably closer to zero than more recently (Kaser et al., 2006; Braithwaite, 2009). First, however, we examine the validity of our assumption of triangular and symmetric area vs altitude distribution.

The World Glacier Inventory is coded according to the instructions of Müller et al. (1977). There are data for a total of 14387 glaciers covering a total area of $53481 \mathrm{~km}^{2}$ for the seven regions (Table 2). Although we do not know accurately the total area of mountain glaciers and ice caps on the globe because the World Glacier Inventory is still not finished, the chosen seven regions probably cover less than $10 \%$ of the global total area (Braithwaite and Raper, 2002). For the present study, the required variables are area, maximum, minimum, and median elevation and primary classification for each glacier.
The instructions of Müller et al. (1977) actually refer to mean altitude but their definition clearly refers to the median altitude of Braithwaite and Müller (1980), although some readers may prefer to follow Kuhn et al. (2009) and call this concept the area-median altitude. We can then compare the median altitude (as defined by us) with the mid-point altitude representing the average of maximum and minimum glacier altitudes (note that many authors incorrectly use the term median for the latter). The difference between median and mid-point altitude is a measure of the asymmetry of the area-altitude distribution. There are missing data for one or other altitude for many glaciers. For example, data are not available at all for median altitude for regions 1,3 and 4 (Axel Heiberg Island, Northern Scandinavia and Southern Norway), and for region 6 (Caucasus) the listed median altitudes are identical to the mid-point altitudes. Glacier inventories for these areas were finished before the instructions of Müller et al. (1977) were available, thus accounting for the omission of median elevation (regions 1, 3 and 4) or its wrong definition (region 6).

The comparison between median and mid-point altitudes could be made for 6976 glaciers in three of the seven regions. However, our conceptual model (Fig. 1) does not apply to "ice caps" and to "outlet glaciers" and we exclude them from the data set, i.e. glaciers with primary classification equal to 3 and 4 according to Müller et al. (1977). Median altitude can then be compared with mid-point altitude for 6831 glaciers. On average there is a remarkably good agreement, with very little difference (mean and standard deviation) between the two altitudes compared with the altitude range of glaciers (Table 3 ). There is also a high correlation and nearly 1:1 relation between the two altitudes (Fig. 3). The assumption of a symmetrical altitude-area distribution in our conceptual model is therefore very sound within a few decametres, e.g. the root-mean-square error of the regression line in Fig. 4 is only $\pm 61 \mathrm{~m}$. We believe that glacier area-altitude distributions may actually be somewhat asymmetric during periods of advance or retreat but the overall effect (Table 3) is small: presumably the sample of 6831 glaciers contains a mixture of retreating, stationary and advancing glaciers.

With a view to modelling the hundreds of thousands of the worlds glaciers for the sea level contribution of glacier melt, we are interested in identifying regional differences in glacier response. Oerlemans (2007) has shown that individual glaciers adjacent to each other can differ in their response times due to different geometry. This can be thought of as noise superimposed on a common signal of glacier response in a region determined by the regional climate and topography. In the empirical derivation of regional scaling indices that follows, we assume that a typical glacier growing or shrinking in a region will in general still have its geometrical dimensions governed by that region's topographical relief. According to the scaling relation Eq. (8), altitude range is linked to area and we estimate the scaling parameter $\eta$ by regression analysis of data from the glacier inventory. There 
Table 3. Asymmetry of altitude-area distributions as expressed by the median and mid-point altitudes for 6831 glaciers (excluding ice caps).

\begin{tabular}{lr}
\hline Concept & Mean and standard deviation \\
\hline Difference between median and mid-point altitudes & $-3 \pm 62 \mathrm{~m}$ \\
Altitude range & $417 \pm 340 \mathrm{~m}$ \\
Difference/Altitude range & $-1 \pm 12 \%$ \\
\hline
\end{tabular}

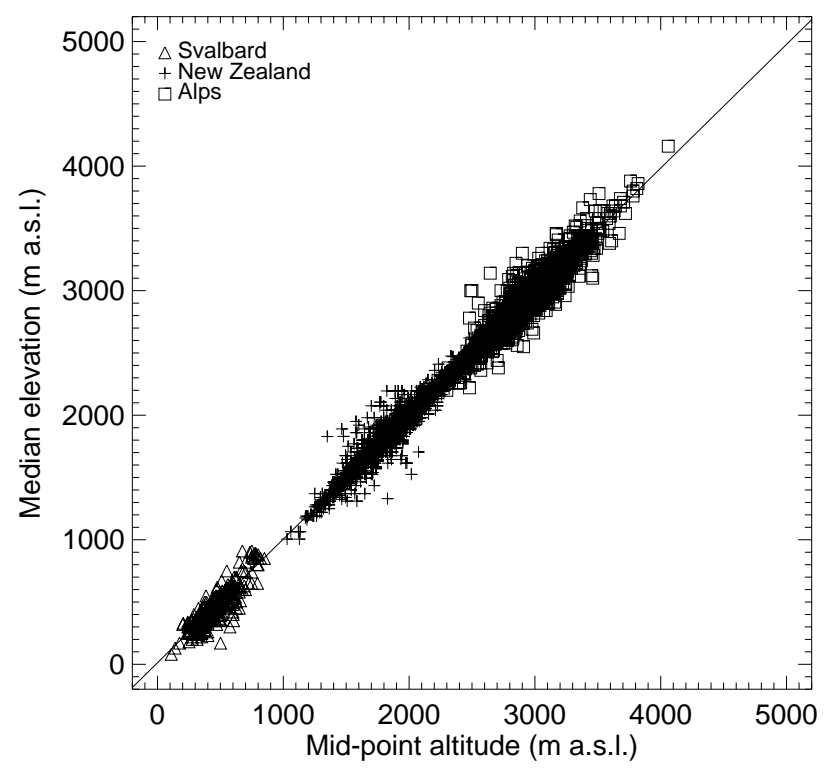

Fig. 3. Median elevation plotted against mid-point elevation for 6831 glaciers in three regions (excluding ice caps).

are two ways that this could be done: nonlinear regression with the original data for range and area or linear regression with logarithms of range and area. Results are fairly similar but the first approach gives a better fit to the larger glaciers.

The non-linear regression of altitude range on area gives a better fit to the larger glaciers because the root-mean-square (RMS) errors are given their full weight. When logarithms are taken the weights are reduced by the corresponding orders of magnitude. The influence of any observation on the regression line is related to the "distance" between the observation and the regression line. Taking logarithms will disproportionately reduce the "distances" for cases with the largest values. This might allow the (numerous) very small glaciers to have undue influence in determining the position of the best-fit line, to the detriment of its fit to the (fewer) larger glaciers. The effect is exacerbated by the uneven distribution of the observations. Only in the case of the fit of the regression to the observations being perfect, with zero RMS error, would the fit using both methods be the same. Statistical results for the nonlinear regression equation $R \propto A^{\eta}$ are given in Table 4 for each of the seven regions. The regression lines from the nonlinear analysis are re-plotted as straight lines in $\log$-log space in Fig. 4 to illustrate the overall fit of the data.

The estimated values of $\eta$ in Table 4 are rather similar $(0.3$ to 0.4 ) for six of the regions but relatively low (0.07) for Svalbard. The latter is clearly anomalous and must be partly due to the omission of smaller glaciers $\left(<1 \mathrm{~km}^{2}\right)$ from the glacier inventory compared with the other regions in Fig. 4. As well as supplying us with estimates of $\eta$ for our response time Eq. (15), the regression analysis allows us to identify typical altitude ranges for a selection of glacier areas to explore response times for generic glaciers (see below).

\section{The volume response time for seven regions}

Using the formula for volume response time $\tau$ in Eq. (15) we make calculations for some generic glaciers to illustrate the effects of differing geometry and climate regime (Table 5). Results are calculated for glacier areas of $1,10,50 \mathrm{~km}^{2}$ respectively with corresponding scaled glacier depths of 28, 65 and $117 \mathrm{~m}$ respectively (for $\gamma=1.36$ ). The altitude ranges for the generic glaciers are given in Table 5, using the $\eta$ value for the region in question.

Some work on response time has suggested it should increase with glacier size, e.g. Table 13.1 in Paterson (1994), but Bahr et al. (1998) found that under certain conditions the response time will decrease as size increases. In seeming confirmation of this, Oerlemans et al. (1998) found "No straightforward relationship between glacier size and fractional change of ice volume". In our Table 5 response time does increase with area for regions 1 and 2 (Axel Heiberg Island and Svalbard), hardly increases in regions 3, 4 and 5 (Northern Scandinavia, Southern Norway and the Alps), and decreases in regions 6 and 7 (Caucasus and New Zealand). The reasons for this can be understood by looking at the detailed breakdown in Table 5.

The reciprocal of balance gradient in line 4 of Table 5 has the units of time (a) and expresses the basic effect of climate on response time with a range of $10^{2}$ to $10^{3} \mathrm{a}$, from the warm-wet (maritime) climate of New Zealand to the cold-dry (continental) climate of Axel Heiberg Island. Regions 1 and 2 both represent arctic islands but region 1 is obviously more continental than region 2. Balance gradients in regions 3, 4, 5 and 6 are quite similar while there is a further jump to the very maritime climate of region 7 . This order of magnitude 
Table 4. Parameter results from non-linear regression between altitude range $R$ and area $A$ for seven regions.

\begin{tabular}{lcccc}
\hline Region & $R \pm 1 \mathrm{SD}(\mathrm{m})$ (range for area $\left.=1 \mathrm{~km}^{2}\right)$ & $\eta \pm 1 \mathrm{SD}$ & Correlation coefficient & Glaciers \\
\hline Axel Heiberg Island & $366 \pm 8$ & $0.30 \pm 0.008$ & 0.67 & 777 \\
Svalbard & $562 \pm 27$ & $0.07 \pm 0.014$ & 0.28 & 271 \\
N Scandinavia & $387 \pm 0$ & $0.34 \pm 0.000$ & 0.72 & 1307 \\
S Norway & $363 \pm 5$ & $0.31 \pm 0.008$ & 0.72 & 823 \\
The Alps & $710 \pm 4$ & $0.35 \pm 0.004$ & 0.73 & 5291 \\
The Caucasus & $730 \pm 8$ & $0.40 \pm 0.007$ & 0.73 & 1192 \\
New Zealand & $729 \pm 5$ & $0.37 \pm 0.003$ & 0.78 & 2744 \\
\hline
\end{tabular}

Table 5. Parameters and variables needed to calculate response times for three different values of glacier area in seven different regions. Regions are (1) Axel Heiberg Island, (2) Svalbard, (3) Northern Scandinavia, (4) Southern Norway, (5) Alps, (6) Caucasus and (7) New Zealand.

\begin{tabular}{lrrrrrrrrr}
\hline Region & & & 1 & 2 & 3 & 4 & 5 & 6 & 7 \\
\hline Variable & Units & Symbol & & & & & & \\
\hline Volume-area parameter & & $\gamma$ & 1.36 & 1.36 & 1.36 & 1.36 & 1.36 & 1.36 & 1.36 \\
Range-area parameter & & $\eta$ & 0.30 & 0.07 & 0.34 & 0.31 & 0.35 & 0.40 & 0.37 \\
Thickness-range parameter & & $\gamma-1-\eta$ & 0.06 & 0.29 & 0.02 & 0.05 & 0.01 & -0.04 & -0.01 \\
Reciprocal of balance-gradient & $\mathrm{a}$ & $1 / \mathrm{k}$ & 1111 & 455 & 250 & 204 & 233 & 208 & 108 \\
Reference depth for area $1 \mathrm{~km}^{2}$ & $\mathrm{~m}$ & $D_{0}$ & 28 & 28 & 28 & 28 & 28 & 28 & 28 \\
Reference depth for area $10 \mathrm{~km}^{2}$ & $\mathrm{~m}$ & $D_{0}$ & 65 & 65 & 65 & 65 & 65 & 65 & 65 \\
Reference depth for area $50 \mathrm{~km}^{2}$ & $\mathrm{~m}$ & $D_{0}$ & 117 & 117 & 117 & 117 & 117 & 117 & 117 \\
Altitude range for area $1 \mathrm{~km}^{2}$ & $\mathrm{~m}$ & $R_{0}$ & 366 & 562 & 388 & 363 & 710 & 730 & 729 \\
Altitude range for area $10 \mathrm{~km}^{2}$ & $\mathrm{~m}$ & $R_{0}$ & 723 & 664 & 841 & 744 & 1592 & 1853 & 1727 \\
Altitude range for area $50 \mathrm{~km}^{2}$ & $\mathrm{~m}$ & $R_{0}$ & 1165 & 747 & 1445 & 1227 & 2799 & 3552 & 3155 \\
Thickness/Range for area $1 \mathrm{~km}^{2}$ & - & $D_{0} / R_{0}$ & 0.077 & 0.052 & 0.072 & 0.077 & 0.039 & 0.038 & 0.038 \\
Thickness/Range for area $10 \mathrm{~km}^{2}$ & - & $D_{0} / R_{0}$ & 0.090 & 0.098 & 0.077 & 0.087 & 0.041 & 0.035 & 0.038 \\
Thickness/Range for area $50 \mathrm{~km}^{2}$ & - & $D_{0} / R_{0}$ & 0.100 & 0.157 & 0.081 & 0.095 & 0.042 & 0.033 & 0.037 \\
Response time for area $1 \mathrm{~km}^{2}$ & $\mathrm{a}$ & $\tau$ & 771 & 880 & 144 & 138 & 71 & 54 & 30 \\
Response time for area $10 \mathrm{~km}^{2}$ & $\mathrm{a}$ & $\tau$ & 906 & 1729 & 155 & 156 & 74 & 50 & 30 \\
Response time for area $50 \mathrm{~km}^{2}$ & $\mathrm{a}$ & $\tau$ & 1012 & 2766 & 162 & 171 & 76 & 47 & 29 \\
\hline
\end{tabular}

climate influence on the glacier volume response time is then modified by geometric factors.

With reference to Table 5 , the geometric factor $R_{0}$ differs by a factor of 3 between regions $1-4$ and regions 5-7 and has a corresponding influence on the volume response times. The geometric factor that determines how the volume response time depends on glacier size is the depth-range ratio, $D_{0} / R_{0}$ (the middle factors of Eq. 15), which scales as $A_{0}^{\gamma-1-\eta}$. In Table 5, the index $\gamma-1-\eta$ is either small positive or small negative, aside from anomalous results for region 2 (Svalbard). Examination of Table 5 shows that for the regions with negative index $\gamma-1-\eta, D_{0} / R_{0}$ decreases with increasing glacier area, leading to shorter response times for larger glaciers in regions 6 and 7 .

We suggest that the larger values of $\eta$ in regions 6 and 7 and the associated larger altitudinal ranges for relatively big glaciers (for example of area $10 \mathrm{~km}^{2}$, which is well within the data range for all seven regions) are related to regional topography. High values of $\eta$ indicate rapidly increasing altitudinal range with increasing glacier area and may be associated with steeper terrain as suggested by Raper and Braithwaite $(2005,2006)$. We hope to explore this issue in a future study using data from other regions with even greater altitude ranges.

We are not able to differentiate between different regions in our volume-area scaling and we simply use the scaling factor $\gamma=1.36$ from Bahr et al. (1997). This means we have to assume a single glacier depth for a particular area in Table 5 but we speculate that a regionally-specific glacier depth would further increase the range of response times shown in Table 5. The reasoning is that glaciers in regions with high topographic relief, with large altitude ranges, are likely 


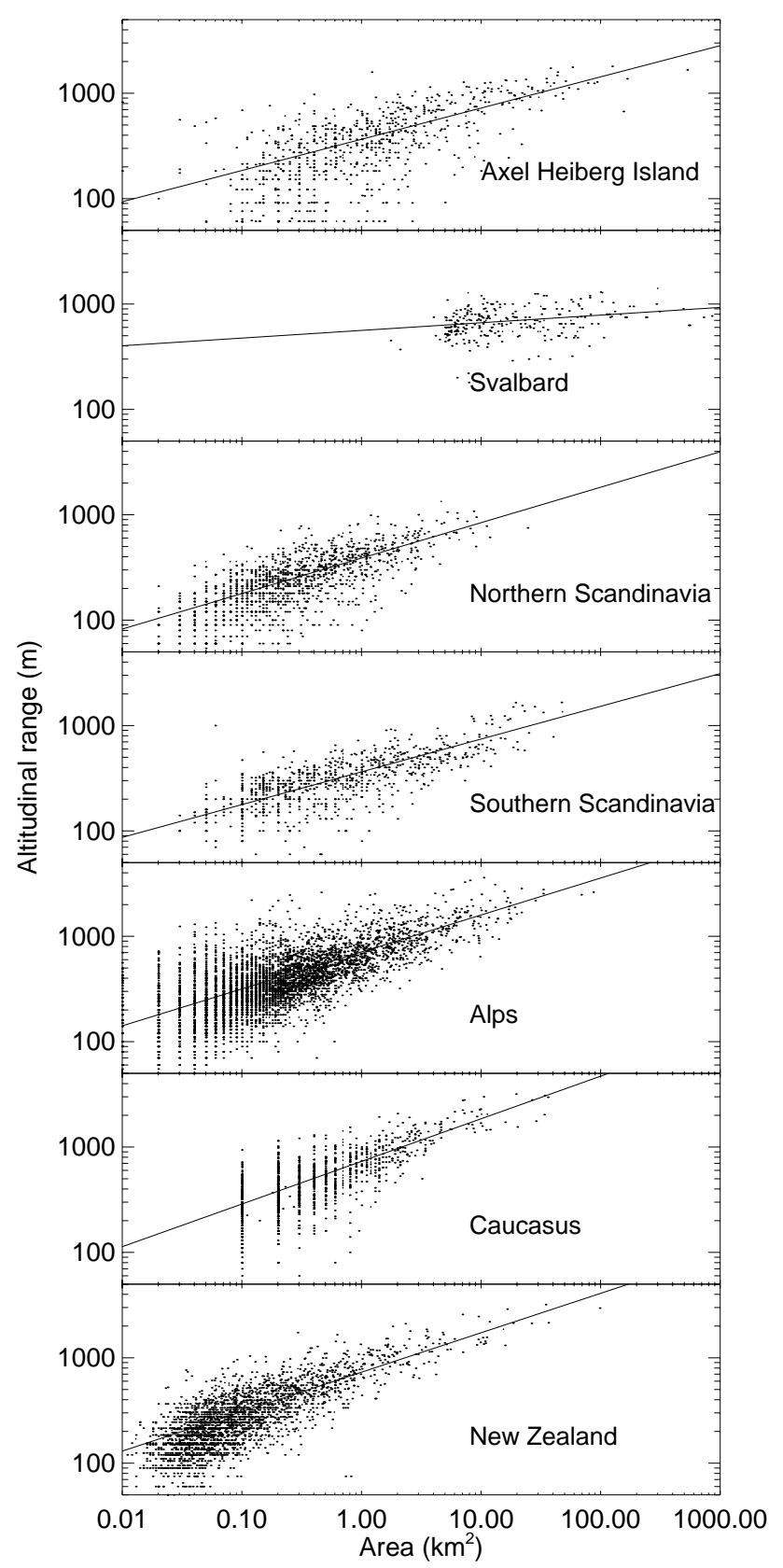

Fig. 4. Log-log plot of glacier altitudinal range versus area for different regions. Solid lines are re-plots of the nonlinear regression curves fitted to the raw data.

to be faster flowing and thinner (smaller $D_{0}$ ) than those in relatively flat terrain, thus further reducing already short response times.

\section{Discussion}

Using an average value (excluding Svalbard) of $\eta$ of 0.35 , then according to Eq. (27) our response time $\tau_{R B}$ is about 2.9 times longer than $\tau_{\mathrm{JRW}}$, the response time of Jóhannesson et al. (1989a). An $\eta$ value of unity $(R \propto A)$ is implicit in the glacier of unit or uniform width with all area changes at the terminus assumed by Jóhannesson et al. (1989a). Radic et al. (2007) also used a glacier of uniform width (and slope) in a comparison of a flow line model with a scaling model.

As a simple experiment with our conceptual model for triangular area-altitude distribution (Fig. 1), we calculated altitude range $R_{1}$ and the corresponding area-altitude distribution for different values of $\eta$ when the area shrinks from $A_{0}$ to $A_{1}$. For $\eta>0.5$, a large reduction in range to $R_{1}$ would result in the dashed line above $R_{1} / 2$, in Fig. 1, being above the solid line joining the top of the glacier to $R_{0} / 2$. This is equivalent to a raising of the glacier surface due to thickening in the accumulation area as the total area is reduced, which is clearly unrealistic. For $\eta=0.5$, the solid and dashed lines above $R_{1} / 2$ in Fig. 1 would coincide, implying no change in area or surface altitude above the new ELA for a change in area from $A_{0}$ to the smaller $A_{1}$. The geometry changes that occur for $\eta<0.5$ as shown in Fig. 1 are consistent with a lowering of the glacier surface due to thinning in both accumulation and ablation areas, when going from $A_{0}$ to the smaller $A_{1}$. Thus the formulation of the model in the vertical area-altitude dimension allows the mass balance-elevation feedback associated with both the area reduction and lowering of the glacier surface to be accounted for. Our empirically derived values of $\eta$ of $0.3-0.4$ are consistent with the geometric expectations that $\eta<0.5$. In accord with our results, Oerlemans (2001, Table 8.3) found that, when applied to four real glaciers, his flow line model gave glacier volume response times that are longer than implied by the Jóhannesson et al. (1989a) formula. Jóhannesson et al. (1989a,b) do realise that their crucial assumption (see above) means that balance-elevation feedback is not accounted for and that their response time estimates may therefore be too short. Harrison et al. (2001) attempt to correct this by including a term that explicitly addresses the balance-elevation feedback, but they still assume that all the area change is close to the terminus. Their treatment may not account for area-altitude changes remote from the region of the terminus, i.e. in the accumulation area.

Our modelling of both mass balance and glacier area in the vertical dimension means that the mass balance elevation feedback resulting from both changes in total area and changes in height of the glacier surface are accounted for. The situation is not so clear when modelling is orientated along the glacier length (or horizontally) as in Radic et al. (2008), who say "The scaling methods applied here include feedback due to changes in area-elevation distribution, but lack the mass-balance/thickness feedback, i.e. the glacier area may change, but the thickness along the glacier profile does not". We find this statement puzzling since logically changes in the area-elevation distribution should reflect changes in glacier thickness.

Due to lack of data we are not able to estimate regionally specific values for $\gamma$, though we might expect lower/higher 
values of $\gamma$ to be associated with lower/higher topographic relief. This issue should be resolved by extending the dataset by depth-sounding or other means (Farinotti et al., 2009; Fischer, 2009) of estimating glacier volume for many more glaciers, especially in regions with high topographic relief. We note that changes in sub-glacial hydrology or in thermal conditions at the glacier bed may also have an effect on $\gamma$.

\section{Conclusions}

We propose a new derivation of the volume response time where the climate and geometric parameters are separated. The volume response time depends directly upon the mean glacier thickness, and indirectly on glacier altitude range and vertical mass-balance gradient. Our formula can be reduced to the well-known ratio of glacier thickness to mass balance at the glacier terminus (Jóhannesson et al., 1989a) but involves an extra numerical factor. This factor increases our volume response time by a factor of about 2.9 compared with that of Jóhannesson et al. (1989a) and reflects the mass balance elevation feedback.

Volume response time depends inversely on the vertical mass balance gradient so, everything else being equal, warm/wet glaciers tend to have shorter response times and cold/dry glaciers tend to have longer response times.

Our model is derived for glaciers whose area distribution is assumed to be symmetrical around the equilibrium line altitude (ELA). It is long known that in steady-state the ELA is approximately equal to median glacier altitude and we now confirm that the mid-point altitude is approximately equal to median altitude.

The scaling parameter between glacier-altitude range and area varies between regions such that volume response time can increase with area (Axel Heiberg Island and Svalbard), hardly change (Northern Scandinavia, Southern Norway and the Alps), or even get smaller (Caucasus and New Zealand).

Acknowledgements. The authors are indebted to Tim Osborn, Climatic Research Unit, University of East Anglia, for many useful discussions. Roger Braithwaite's main work on this paper was made during a period of research leave from the University of Manchester (Summer 2008) and he thanks colleagues for covering his teaching and administration duties. The constructive comments of the scientific editor Shawn Marshall and the interactive comments from Mauri Pelto, and reviewers Surendra Adhikari and Michael Kuhn helped to improve the manuscript.

Edited by: S. Marshall

\section{References}

Anonymous: Mass-balance terms, J. Glaciol., 8(52), 3-8, 1969.

Bahr, D. B.: Width and length scaling of glaciers, J. Glaciol., 43(145), 557-562, 1997.
Bahr, D. B.: On fundamental limits to glacier flow models: computational theory and implications, J. Glaciol., 47(159), 659-664, 2009.

Bahr, D. B., Meier, M. F., and Peckham, S. D.: The physical basis of glacier volume-area scaling, J. Geophys. Res., 102, 2035520362, 1997.

Bahr, D. B., Pfeffer, W. T., Sassolas, C., and Meier, M.: Response time of glaciers as a function of size and mass balance: 1 . Theory, J. Geophys. Res., 103, 9777-9782, 1998.

Braithwaite, R. J.: Can the mass balance of a glacier be estimated from its equilibrium-line altitude?, J. Glaciol., 30(106), 364-368, 1984.

Braithwaite, R. J.: After six decades of monitoring glacier mass balance we still need data but it should be richer data, Ann. Glaciol., 50(50), 191-197, 2009.

Braithwaite, R. J. and Müller, F.: On the parameterization of glacier equilibrium line altitude. World Glacier Inventory - Inventaire mondial des Glaciers (Proceeding of the Riederalp Workshop, September 1978: Actes de l'Ateliere de Riederalp, september 1978). IAHS-AISH 127, 273-271, 1980.

Braithwaite, R. J. and Zhang, Y.: Modelling changes in glacier mass balance that may occur as a result of climate changes, Geogr. Ann. A., 81(4), 489-496, 1999.

Braithwaite, R. J. and Raper, S. C. B.: Glaciers and their contribution of sea level change, Phys. Chem. Earth, 27, 1445-1454, 2002.

Braithwaite, R. J. and Raper, S. C. B.: Glaciological conditions in seven contrasting regions estimated with the degree-day model, Ann. Glaciol. 46, 297-302, 2007.

Callendar, G. S.: Note on the relation between the height of the firn line and the dimensions of a glacier, J. Glaciol., 1(8), 459-461, 1950.

Callendar, G. S.: The effect of the altitude of the firn area on a glacier's response to temperature variations, J. Glaciol., 1(9), 573-576, 1951.

Chen, J. and Ohmura A.: Estimation of alpine glacier water resources and their change since the 1870s, IAHS Publ., 193, 127135, 1990.

De Woul, M. and Hock, R.: Static mass-balance sensitivity of arctic glaciers and ice caps using a degree-day approach, Ann. Glaciol., 42, 217-224, 2005.

Elsberg, D. H., Harrison, W. D., Echelmeyer, K. A., and Krimmel, R. M.: Quantifying the effects of climate and surface change on glacier mass balance, J. Glaciol., 47(159), 649-658, 2001.

Farinotti, D., Huss, M., Bauder, A., Funk, M. and Truffer, M.: A method to estimate ice volume and ice thickness distribution of alpine glaciers, J. Glaciol., 55(191), 422-430, 2009

Fischer, A.: Calculation of glacier volume from sparse ice-thickness data, applied to Schaufelferner, Austria, J. Glaciol., 55(191), 453-460, 2009

Furbish, D. J. and Andrews, J. T.: The use of hypsometry to indicate long-term stability and response of valley glaciers to changes in mass transfer, J. Glaciol. 30(105), 199-211, 1984.

Haeberli, W., Hoelzle, M., Paul, J., and Zemp, M.: Integrated monitoring of mountain glaciers as key indicators of global climate change: the European Alps, Ann. Glaciol., 46, 150-160, 2007.

Harrison, W. D., Elsberg, D. H., Echelmeyer, K. A., and Krimmel, R. M.: On the characterization of glacier response by a single time-scale, J. Glaciol., 47(159), 659-664, 2001. 
IPCC, Climate Change: The Physical Sciences Basis. Contribution of Working Group I to the Fourth Assessment Report of the Intergovernmental Panel on Climate Change, edited by: Solomon, S., Qin, D., Manning, M., Chen, Z., Marquis, M., Averyt, K. B., Tignor, M., and Miller, H. L., Cambridge University Press, Cambridge, U K and New York, N.Y., USA, 996 pp., 2007.

Jóhannesson, T., Raymond, C. F., and Waddington, E. D.: A simple method for determining the response time of glaciers, edited by: Oerlemans, J., Glacier Fluctuations and Climate Change, Kluwer, 407-417, 1989a.

Jóhannesson, T., Raymond, C.F., and Waddington, E.D.: Timescale for adjustments of glaciers to changes in mass balance ,J. Glaciol., 35(121), 355-369, 1989b.

Kaser, G., Cogley, J. G., Dyurgerov, M. B., Meier, M. F., and Ohmura, A.: Mass balance of glaciers and ice caps: Consensus estimates for 1961-2004, Geophs. Res. Lett., 33, L19501, doi:10.1029/2006GL027511, 2006.

Kuhn, M.: The response of the equilibrium line altitude to climate fluctuations: theory and observations, eited by: Oerlemans, J., Glacier Fluctuations and Climate Change, Kluwer, 407-417, 1989.

Kuhn, M.: Interactive comment on "Glacier volume response time and its links to climate and topography based on a conceptual model of glacier hypsometry" by S. C. B. Raper and R. J. Braithwaite, The Cryosphere Discussions, 3, C69-C73, 2009.

Kuhn, M., Abermann, J., Bacher, M., and Olefs M.: The transfer of mass-balance profiles to unmeasured glaciers, Ann. Glaciol., 50(50), 185-190, 2009.

Kurowski, L.: Die Höhe der Schneegrenze mit besonderer Berücksichtigung der Finsteraarhorne-Gruppe, Penck's Geogr, Abhandlungen 5(1), 119-160, 1893.

Lüthi, M., Funk, M., and Bauder, A.: Comment on "Integrated monitoring of mountain glaciers as key indicators of global climate change: the European Alps", J. Glaciol., 54(184), 199-200, 2008.

Meier, M. F.: Proposed definitions for glacier mass budget terms, J. Glaciol., 4(33), 252-273, 1962.

Meier, M. F.: Contribution of small glaciers to global sea level, Science, 227, 1418-1421,1984.

Meier, M. F. and Post, A. S.: Recent variations in mass net budgets of glaciers in western North America, Variations du regime des glaciers existants - Variations of the regime of existing glaciers, Proceeding of the Obergurgl Symposium, September 1962, IAHS-AISH 58, 63-77, 1962.

Müller, F., Caflisch, T., and Müller, G.: Instructions for the compilation and assemblage of data for a world glacier inventory, Zürich, ETH Zürich, Temporary Technical Secretariat for the World Glacier Inventory, 293 pp., 1977.

Nye, J. F.: The flow of glaciers, Nature, 161(4099), 819-821, 1948.

Nye, J. F.: On the theory of the advance and retreat of glaciers, Geophys. J. Roy. Astr. S., 7(4), 431-456, 1963.

Pfeffer, W. T., Sassolas, C., Bahr, D. B., and Meier, M.: Response time of glaciers as a function of size and mass balance: 2 . Numerical experiments, J. Geophys. Res., 103, 9777-9782, 1998.

Oerlemans, J. and Fortuin, J. P. F.: Sensitivity of glaciers and small ice caps to Greenhouse warming, Science, 258, 115-117, 1992.

Oerlemans, J.: Modelling of glacier mass balance, in: Ice in the climate, edited by: Peltier, W. R., Berlin and Heidelberg, SpringerVerlag, 101-116, 1993.
Oerlemans, J., Anderson, B., Hubbard, A., Huybrechts, P., Jóhannesson, T., Knap, W. H., Schmeits, M., Stroeven A. P., van de Wal, R. S. W., Wallinga, J., and Zuo, Z.: Modelling the response of glaciers to climate warming, Clim, Dynam. 14, 277274, 1998.

Oerlemans, J.: Glaciers and climate change, Lisse, etc., A. A. Balkema, 2001.

Oerlemans, J.: Estimating response times of Vadret da Morteratsch, Vadret da Palu, Briksdalsbreen and Nigardsbreen from their length records, J. Glaciol., 53(182), 357-362, 2007.

Paterson, W. S. B.: Laurentide ice sheet: estimated volumes during the late Wisconsin, Review of Geophysics and Space Physics 10, 885-917, 1972.

Paterson, W. S. B.: The physics of glaciers, (2nd edition), Pergamon, Oxford, 380 pp., 1981.

Paterson, W. S. B.: The physics of glaciers, (3rd edition), Pergamon, Oxford, 480 pp., 1994.

Paul, F., Kaab, A., Maisch, M., Kellenberger, T., and Haeberli, W.: Rapid disintegration of Alpine glaciers observed with satellite data, Geophys. Res. Lett., 31, L21402, doi:10.1029/2004GL020816, 2004.

Pelto, M.: The current disequilibrium of North Cascade glaciers, Hydrol. Process., 20, 769-779, 2006.

Radic, V., Hock, R., and Oerlemans, J.: Volume-area scaling vs flowline modelling in glacier volume projections, Ann. Glaciol., 46, 234-240, 2007.

Radic, V., Hock, R., Oerlemans, J.: Analysis of scaling methods in deriving future volume evolutions of valley glaciers, J. Glaciol., 5(187), 1-12, 2008.

Raper, S. C. B., Briffa, K. R., and Wigley, T. M. L.: Glacier change in northern Sweden from AD500: a simple geometric model of Storglaciären, J. Glaciol., 42(141), 341-351, 1996.

Raper, S. C. B., Brown, O., and Braithwaite, R. J.: A geometric glacier model for sea level change calculations,. J. Glaciol., 46(154), 357-368, 2000.

Raper, S. C. B. and Braithwaite, R. J.: The potential for sea level rise: new estimates from glacier and ice cap area and volume distributions, Geophys. Res. Lett., 32(7), L05502, doi:10.129/2004GL021981, 2005.

Raper, S. C. B. and Braithwaite, R. J.: Low sea level rise projections from mountain glaciers and icecaps under global warming, Nature, 439(7074), 311-313, 2006.

Shumsky, P. A.: The energy of glacierization and the life of glaciers, English translation in Kotlyakov, V. M. (editor) 1997, 34 selected papers on main ideas of the Soviet Glaciology, 1940a-1980s, Moscow, Russian Academy of Sciences, 1947 (in Russian).

Van de Wal, R. S. W. and Wild, M.: Modelling the response of glaciers to climate change by applying the volume-area scaling in combination with a high resolution GCM, Clim. Dynam., 18, 359-366, 2001.

Warrick, R. A. and Oerlemans, J.: Sea level rise. In Climate change - The IPCC Scientific Assessment, edited by: Houghton, J. T., Jenkins, G. J., and Ephraums, J. J., Cambridge, Cambridge University Press, 358-405, 1990.

World Glacier Inventory, World Glacier Monitoring Service and National Snow and Ice Data Center/World Data Center for Glaciology. Boulder, CO, Digital media, 1999, updated 2005. 